\title{
PAPER
}

\section{Progressive ventricular enlargement in patients with clinically isolated syndromes is associated with the early development of multiple sclerosis}

\author{
C M Dalton, P A Brex, R Jenkins, N C Fox, K A Miszkiel, W R Crum, J I O'Riordan, \\ G T Plant, A J Thompson, D H Miller
}

J Neurol Neurosurg Psychiatry 2002;73:141-147

See end of article for authors' affiliations

Correspondence to:

Professor D H Miller, NMR

Research Group, Institute of Neurology, Queen Square, London WCIN 3BG, UK:

d.miller@ion.ucl.ac.uk

Received

3 December 2001

In revised form

28 February 2002

Accepted 3 May 2002

Background: In patients with clinically isolated syndromes (CIS) suggestive of multiple sclerosis (MS),
the extent of brain magnetic resonance imaging (MRI) lesion load influences the probability and time to development of clinically definite MS. Cerebral atrophy is recognised in established MS, but its time of onset and whether, in early disease, it is related to MRI lesion load or clinical outcome is less certain.

Objectives: This study investigated ventricular enlargement over one year in CIS patients and explored its relation with lesion load and clinical outcome.

Methods: A semi-automated thresholding technique for measuring ventricular volume (MIDAS) was applied to MRI scans in a cohort of 55 patients with CIS, recruited consecutively and imaged within three months of the onset of symptoms and again after one year.

Results: Clinical MS had developed after one year in 16 of 40 patients with an abnormal baseline T2 scan and 2 of 15 with a normal scan. Significant ventricular enlargement was seen in 27 of 55 patients who fulfilled the new McDonald MRI criteria for MS using all available MRI at clinical follow up (median increase $0.3 \mathrm{~cm}^{3}, p=0.005$ ) Significant increase in ventricular volume was also seen in the 18 of 55 patients who developed clinical MS over the follow up period (median increase $0.5 \mathrm{~cm}^{3}$, $p=0.006$ ). There were significant but modest correlations between baseline lesion measures and subsequent ventricular enlargement.

Conclusions: (1) Lesions and atrophy are both associated with early relapse leading to a diagnosis of clinical MS; (2) while lesions contribute to the development of atrophy, atrophy may also develop by other mechanisms. This suggests that MR measures have a complementary role in monitoring the course of $M S$, even from the earliest clinical stage.

$\mathrm{P}$ revious radiological and pathological studies have established that whole brain ${ }^{1-3}$ and spinal cord atrophy ${ }^{45}$ occur in multiple sclerosis (MS) in excess of that expected with age. In one study, progressive cerebral atrophy over one year has been detected using registered, volumetric magnetic resonance imaging (MRI) to measure both brain and ventricular volumes, ${ }^{6}$ with a rate of cerebral atrophy in MS shown to be twice that seen in normal controls and the rate of ventricular enlargement five times that of controls. There was also a good correspondence between global brain atrophy and ventricular enlargement. ${ }^{\circ}$

While the mechanisms of atrophy in MS are not well understood, it probably indicates loss of functionally important structures: myelin and axons that are the majority bulk of brain white matter, although variable effects on tissue volumes may also arise from glial cell proliferation or loss, gliosis, inflammation, and oedema. ${ }^{7}$ A correlation between reduced cerebral white matter $\mathrm{N}$-acetyl aspartate (NAA) (a neuronal marker) and cerebral atrophy suggest that axonal loss may make a contribution. ${ }^{8}$ However, the relation between atrophy and decreased NAA is non-linear, ${ }^{9}$ and factors other than axonal loss are also likely to effect these MR measures. In general, disability in MS has been more strongly correlated with measures of atrophy than lesion load. ${ }^{10}{ }^{11}$ However, only modest correlations between atrophy and lesion load have been observed..$^{12}$ This could indicate that atrophy develops by mechanisms, some of which are independent of lesions, or that there is a temporal dissociation between lesion accumu- lation that occurs early in the disease process and atrophy, which occurs late.

To investigate the onset of atrophy and its relation to lesions and clinical events, we studied patients presenting with clinically isolated syndromes (CIS) suggestive of MS. The study of this cohort permits an investigation into the earliest clinical stages of MS, as long term follow up indicates that the majority of CIS patients with MRI brain lesions will go on to develop clinically definite MS. ${ }^{14-17}$ In this report, atrophy was evaluated using a measure of ventricular enlargement. This study follows a previous preliminary pilot study of a small, selected group of 17 from within the present larger cohort of 55 patients. ${ }^{18}$ The purposes of the study were:

1 To confirm the preliminary study showing that measurable ventricular enlargement develops over one year in some patients with patients with CIS.

2 To clarify whether ventricular enlargement is associated with the early development of MS, using conventional clinical criteria and the new McDonald criteria.

3 To determine the relation between ventricular enlargement and MR measurements of lesion load at this early stage of disease.

Abbreviations: $\mathrm{CIS}$, clinically isolated syndromes; MS, multiple sclerosis; MRI, magnetic resonance imaging; NAA, N-acetyl aspartate 


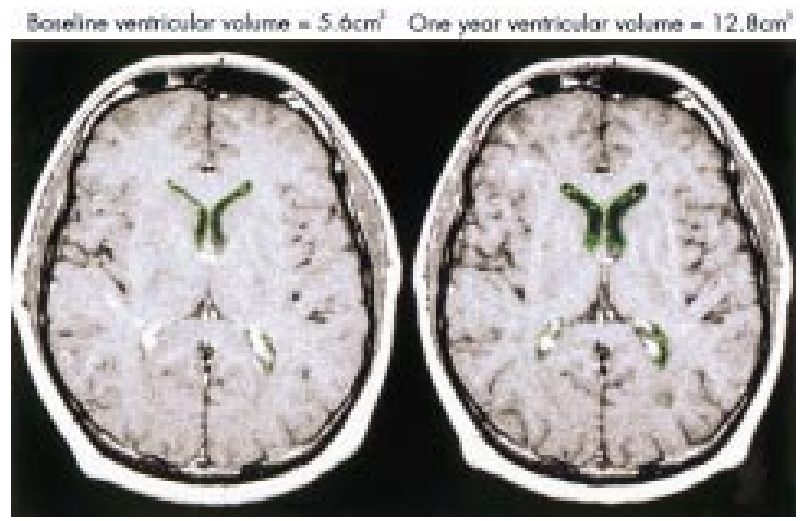

Figure 1 Ventricular segmentation: seeds are inserted into the lateral ventricules and temporal horns. The third and fourth ventricules are excluded. High signal choroid is excluded. This 29 year old man presented with left optic neuritis in 1998. Two months later he developed numbness on the right side of his face. He had approximately three relapses between his baseline and one year scans.

\section{METHODS \\ Patients}

We recruited adult patients, aged between 17 and 50 years, who presented to our clinics at Moorfields Eye Hospital or the National Hospital for Neurology and Neurosurgery with CIS suggestive of MS. Appropriate investigations including full blood count, erythrocyte sedimentation rate (ESR), autoantibody screen, syphilis serology, vitamin B12, and brain MRI were used to exclude other diagnoses. Fifty five patients were recruited consecutively from January 1996 until June 1999 (16 patients, recruited before a hardware upgrade to the scanner in January 1996 were excluded from this study because serial evaluations before and after upgrade revealed instability of volume measures. Ongoing quality assurance protocols have confirmed the stability of measurements since January 1996). A CIS was defined as a single event of acute onset in the central nervous system suggestive of demyelination, for example, unilateral optic neuritis, brain stem and partial spinal cord syndromes. Patients with a history of previous neurological symptoms suggestive of demyelination were excluded. Other diagnoses were excluded by appropriate investigations. Overall, 38 patients had optic neuritis, 11 a brain stem syndrome, five a spinal cord syndrome (spinal MRI excluded an alternative structural cause in these cases), and one patient had a hemianopia attributable to an MRI lesion in the optic tract.

The age range at baseline was 17 to 50 years with a median age of 31 years. The upper age limit of 50 years was applied to reduce the likelihood of including patients with white matter lesions attributable to small vessel disease and because onset of MS above this age is less common. Local ethics committees approved the study and informed consent was obtained from each patient before entry.

Patients were imaged on three occasions: (a) at baseline, which in all instances was within three months of the onset of symptoms, (b) approximately three months later, and (c) approximately one year later. Clinical examination and EDSS $^{19}$ were performed at each visit. The diagnosis of clinical MS (clinically definite or probable) was based on the Poser criteria, ${ }^{20}$ using clinical criteria alone (MRI or CSF findings were not incorporated). Clinically definite MS was diagnosed when a second relapse occurred more than one month after the CIS, which involved a separate part of the CNS and was accompanied by new findings on examination. Clinically probable MS was diagnosed when there was a history indicating a new relapse involving a separate location but there were no new signs on examination. The new McDonald MRI crite-

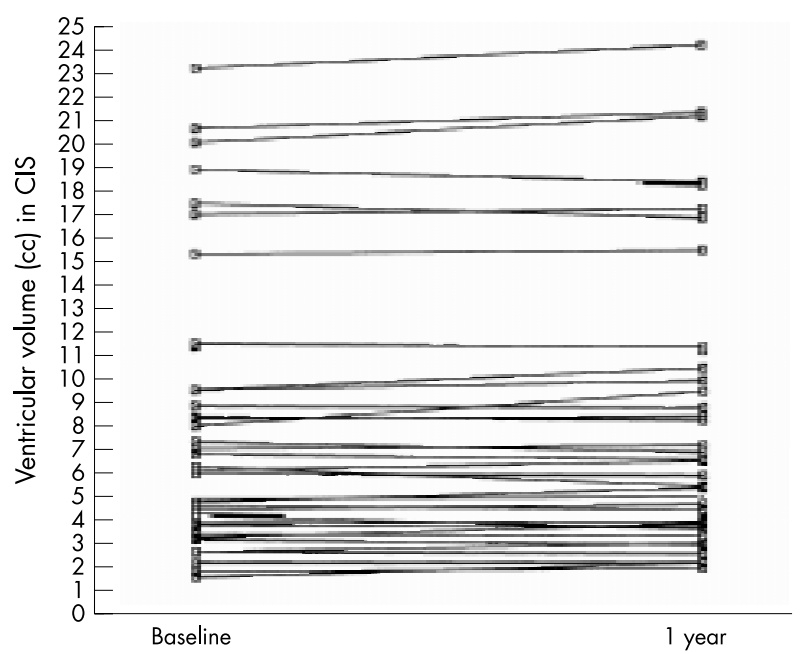

Figure 2 Scatter plot of ventricular volumes at baseline and one year in the 37 patients with CIS at one year.

ria, which additionally permit a diagnosis of MS in CIS patients based on MRI evidence of dissemination of lesions in time and space, were also applied. ${ }^{21}$

\section{Image acquisition}

Brain MRI was performed using a 1.5 Tesla GE scanner. At baseline, three months and one year each, a proton density/T2 weighted fast spin echo (FSE) sequence (repetition time (TR) $3200 \mathrm{~ms}$, effective echo time (TE) 15/95 ms) and a Tl weighted spin echo sequence (TR $600 \mathrm{~ms}$ TE $14 \mathrm{~ms}$ ) were acquired in each patient, with $3 \mathrm{~mm}$ contiguous, axial slices. The matrix used was $256 \times 256$ with a field of view of $24 \mathrm{~cm}$. Each patient was given an intravenous bolus of $0.1 \mathrm{mmol} / \mathrm{kg}$ gadolinium DTPA five to seven minutes before the start of image acquisition.

\section{Ventricle volume measurement}

The ventricles were measured on baseline and one year follow up Tl weighted scans using the MIDAS interactive image analysis package ${ }^{22}$ by a single observer blinded both to patient details and scan acquisition order (the three month scan was not analysed using MIDAS ${ }^{22}$ as it was considered unlikely that change would be detectable over this short period). The initial step was segmentation of the whole brain using a semiautomated interactive morphological technique with the image intensity threshold for the boundary between the CSF and brain set at $60 \%$ mean signal intensity. The inferior cut off was taken at the lowest point of the cerebellum. Ventricular volume consisted of the lateral ventricles and temporal horns but excluded the third and fourth ventricles. This was measured using a semi-automated seed placing technique, involving voxels with an image intensity of less than $60 \%$ of the mean (fig 1). ${ }^{22}$ MIDAS also provides a measure of change in whole brain volume, but on the two dimensional images available for this study, this measure required considerable time and manual editing. The analysis was therefore confined to ventricular volumes only.

\section{Reproducibility of the ventricular measurement technique}

Ten ventricular volumes were measured and re-measured after seven days by a single observer blinded to both patient details and scan acquisition order. The mean coefficient of variation was $0.89 \%$ before starting image analysis.

\section{Lesion identification and lesion load measurement}

The MRI scans were reviewed by an experienced neuroradiologist (KAM), who was blinded to the patients' clinical status at 


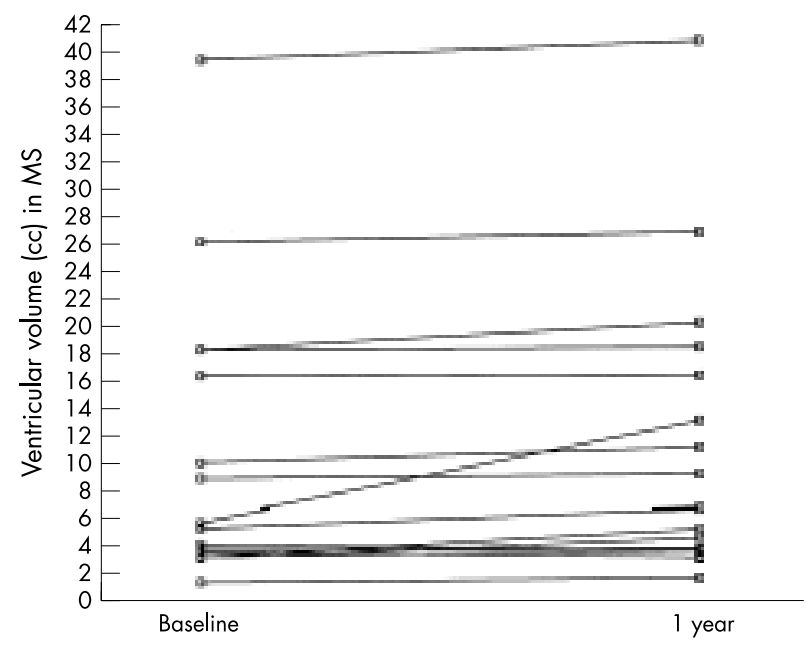

Figure 3 Scatter plot of ventricular volumes at baseline and one year in the 18 patients with MS at one year.

follow up. T2 weighted lesions were identified on the PD weighted images with confirmatory support from the long TE image, on both the baseline and one year follow up scans. Tl hypointense and gadolinium enhancing lesions were identified on the Tl weighted scans. Tl hypointense lesions were identified at baseline and one year follow up. Enhancing lesions were identified on all three scans (baseline, three months, and one year). The volumes of $\mathrm{T} 2$ and $\mathrm{T} 1$ hypointense lesions at baseline and one year were subsequently calculated from electronic data on a Sun Workstation using a semiautomated local thresholding technique to contour the lesions. ${ }^{23}$

\section{Statistical analysis}

Comparison was made between the baseline and one year ventricular volumes using the Wilcoxin signed rank test (tables 2 and 4). The Mann-Whitney U test was used to compare baseline lesion load measures in patients who developed MS and those who had no further symptoms (table 3). Correlations between lesions measures and ventricular volume change were performed using Spearman's non-parametric correlations.

The Bonferroni correction was applied by dividing the number of analyses into 0.05 . The $\mathrm{p}$ value for significance was then calculated at 0.003 (table 5).

\section{RESULTS}

\section{Baseline MRI findings}

The median time delay between the onset of symptoms and baseline scan was six weeks, with a range of 1 to 12 weeks. At baseline, 40 of $55(73 \%)$ patients had one or more lesions detected on T2 weighted MRI, of whom 21 also exhibited one or more hypointense lesions on Tl weighted images and 15 displayed one or more gadolinium enhancing lesions. Ventricular volumes varied considerably between subjects (range $1.2-39.2 \mathrm{~cm}^{3}$; see table 2 , fig 2 and 3 ). There was no significant difference in baseline ventricular volumes in patients depending on sex $(p=0.8)$, with or without T2 lesions $(p=0.3), T 1$ lesions $(p=0.9)$ and gadolinium enhancing lesions $(p=0.2)$ (Mann-Whitney U test for all comparisons). There was no

Table 1 Patient details

\begin{tabular}{lll}
\hline Clinical status & Early MS & Asymptomatic \\
\hline Sex, M/F & $6 / 12$ & $18 / 19$ \\
Age in years median (range) & $30.5(17-49)$ & $31(18-50)$ \\
Weeks from onset to baseline scan median (range) & $6.5(1-12)$ & $5(2-11)$ \\
Months from baseline to year one scan median (range) & $12(11-15)$ & $12(12-16)$ \\
EDSS at baseline median (range) & $1.5(0-8)$ & $2(0-4)$ \\
EDSS at one year median (range) & $2(0-8)$ & $1(0-3)$ \\
\hline Clinical status & McDonald MS & McDonald MS negative \\
\hline Sex, M/F & $10 / 17$ & $14 / 14$ \\
Age in years median (range) & $31(17-47)$ & $31(18-50)$ \\
Weeks from onset to baseline scan median (range) & $5(1-12)$ & $6(2-11)$ \\
Months from baseline to year one scan median (range) & $12(11-16)$ & $12(12-14)$ \\
EDSS at baseline median (range) & $1(0-8)$ & $2(0-4)$ \\
EDSS at one year median (range) & $1(0-8)$ & $1(0-3.5)$ \\
\hline
\end{tabular}

Table 2 Comparison of ventricular volumes in patients who developed clinical MS and McDonald MS versus those who did not develop clinical and McDonald MS

\begin{tabular}{|c|c|c|c|}
\hline & Early MS $n=18$ & Asymptomatic $n=37$ & Total $n=55$ \\
\hline $\begin{array}{l}\text { Baseline ventricular volume } \mathrm{cm}^{3} \text { median (range) } \\
1 \text { year follow up ventricular volume } \mathrm{cm}^{3} \text { median (range) } \\
\ddagger \text { Ventricular volume change } \mathrm{cm}^{3} \text { median (range) }\end{array}$ & $\begin{array}{l}* 5.4(1.2-39.2) \\
* 7.7(1.3-40.6) \\
+0.5(-0.6-7.2)\end{array}$ & $\begin{array}{l}\dagger 6.0(1.5-23.1) \\
\text { †6.2(1.7-24.1) } \\
+0.06(-0.9-1.4)\end{array}$ & $\begin{array}{l}5.9(1.2-39.2) \\
6.3(1.3-40.6) \\
+0.1(-0.9-7.2)\end{array}$ \\
\hline
\end{tabular}

Comparing baseline versus one year ventricular volumes $* \mathrm{p}=0.006, \mathrm{tp}=0.402$

Comparing ventricular volume change in MS $(n=18)$ and those with no further symptoms $(n=37) \neq p=0.007$.

\begin{tabular}{lll}
\hline & McDonald $M S \mathrm{n}=27$ & McDonald MS negative $\mathrm{n}=28$ \\
\hline Baseline ventricular volume $\mathrm{cm}^{3}$ median (range) & ${ }^{*} 6.0(1.2-39.2)$ & $\dagger 5.3(1.7-23.1)$ \\
1 year follow up ventricular volume $\mathrm{cm}^{3}$ median (range) & ${ }^{*} 8.1(1.4-40.6)$ & $\dagger 5.2(1.7-24.1)$ \\
$\ddagger$ Ventricular volume change $\mathrm{cm}^{3}$ median (range) & $+0.3(-0.7-7.2)$ & $+0.05(-0.9-1.4)$
\end{tabular}

Comparing baseline versus one year ventricular volumes ${ }^{*} p=0.005, \dagger p=0.632$. Comparing ventricular volume change in patients with McDonald MRI MS $(n=27)$ and those without $(n=28) \neq p=0.03$. 


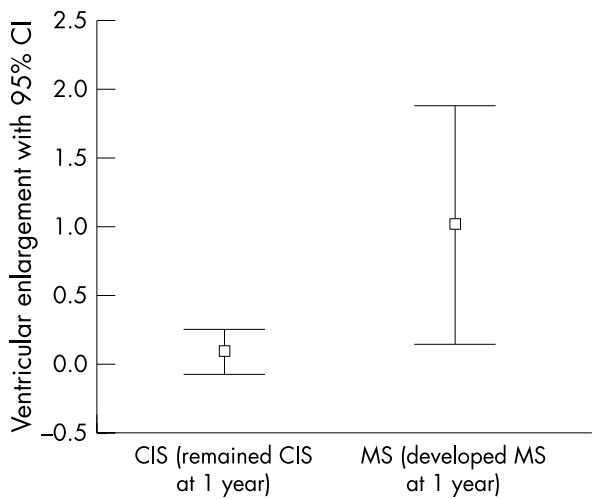

Figure 4 Error bar plot of ventricular enlargement in patients with CIS and MS

correlation between baseline ventricular volume and subsequent atrophy $(r=0.17$ and $\mathrm{p}=0.23)$.

\section{Follow up findings (tables 1-5)}

Clinical outcome

The median time between the baseline and one year follow up was 12 months (range 11-16 months). Thirty seven patients remained asymptomatic, while 18 patients developed clinically definite $(n=14)$ or probable $(n=4)$ MS during the one year follow up period. Sixteen of the 18 patients who developed clinical MS had abnormalities on the T2 scan at baseline.

\section{Relation between lesions and clinical outcome}

The baseline number of $\mathrm{T} 2, \mathrm{~T} 1$ hypointense and gadolinium enhancing lesions was significantly higher in those who went on to develop clinical MS compared with those who did not (table 3). The baseline volumes of $\mathrm{T} 2$ and $\mathrm{T} 1$ hypointense lesions were also significantly higher in those who developed MS (table 3 ).
Relation between ventricular enlargement and clinical outcome

There was a significant increase in ventricular volume over one year in the 18 patients who developed MS during the one year follow up period $(p=0.006$, table 2$)$. A significant increase in ventricular volume was also seen in the 16 patients with T2 lesions at baseline who developed clinical MS at one year (median increase $0.9 \mathrm{~cm}^{3}, \mathrm{p}=0.002$ ). There was no significant correlation between ventricular enlargement and baseline EDSS, month 12 EDSS or change in EDSS over the year, using the Bonferroni correction (table 5).

Relation between ventricular enlargement and the McDonald criteria for MS

The baseline, three month, and one year scans were retrospectively analysed to see how many patients fulfilled the new McDonald criteria for the diagnosis of MS. ${ }^{21}$ Patients with CIS with MRI evidence of dissemination in space and time were diagnosed as having McDonald MRI MS. Twenty seven of the 55 patients were McDonald criteria positive at one year (table 1).

Relation between ventricular enlargement and lesion load measures

Subgroup comparisons (table 4)

Significant ventricular enlargement was seen in the group of 40 patients with $\mathrm{T} 2$ lesions at baseline $(\mathrm{p}=0.001)$ but not in the 15 patients with normal scans at baseline $(\mathrm{p}=0.46$, table $4)$. The 15 patients with gadolinium enhancing lesions at baseline had significant ventricular enlargement at one year $(\mathrm{p}=0.004$, table 4$)$.

The 14 patients who had gadolinium enhancing lesions at three months also showed significant ventricular enlargement at one year (baseline median $5.7 \mathrm{~cm}^{3}$ (2.6-25.9), one year median $\left.6.7 \mathrm{~cm}^{3}(2.9-26.5), \mathrm{p}=0.006\right)$. The seven patients who had enhancing lesions at both baseline and three months exhibited a substantial increase in ventricular volume (baseline median $7.9 \mathrm{~cm}^{3}(3.2-25.9)$, one year median $12.9 \mathrm{~cm}^{3}$ $(3.7-26.5), \mathrm{p}=0.02)$.

Table 3 Comparison of baseline lesion measures in patients who developed MS and those who remained asymptomatic

\begin{tabular}{llll}
\hline & Early MS $(\mathrm{n}=18)$ & Asymptomatic $(\mathrm{n}=37)$ \\
\hline Number of T2 lesions at baseline median (range) & $20(0-70)$ & $2(0-76)$ & 0.001 \\
Volume of T2 lesions lesions at baseline $\mathrm{cm}^{3}$ median (range) & $1.7(0-13.9)$ & $0.3(0-5.2)$ & 0.001 \\
Number of Gd-DTPA lesions at baseline median (range) & $1.5(0-21)$ & $0-13)$ & 0.001 \\
Number of T1 hypointense lesions at baseline median (range) & $1(0-18)$ & $0-2)$ & 0.001 \\
Volume of T1 hypointense lesions at baseline $\mathrm{cm}^{3}$ median (range) & $0.09(0-4.5)$ & $0.6)$ & 0.001 \\
\hline
\end{tabular}

Table 4 Ventricular volumes in patients with normal and abnormal T2 weighted MRI (that is, $\geqslant 1$ T2 lesion) at baseline. Ventricular volumes in patients with abnormal baseline T2 weighted MRI: comparison of those with and without gadolinium (Gd) enhancing and $\mathrm{T} 1$ hypointense lesions

\begin{tabular}{|c|c|c|c|c|c|c|}
\hline & \multicolumn{2}{|c|}{$\begin{array}{l}\text { Normal and abnormal } \\
\text { baseline MRI }(n=55)\end{array}$} & \multicolumn{4}{|c|}{ Abnormal baseline MRI $(n=40)$} \\
\hline & $\begin{array}{l}\text { Normal MRI } \\
(n=15)\end{array}$ & $\begin{array}{l}\text { Abnormal MRI } \\
(n=40)\end{array}$ & $\begin{array}{l}\text { Gd lesions } \\
(n=15)\end{array}$ & $\begin{array}{l}\text { No Gd lesions } \\
(n=25)\end{array}$ & $\begin{array}{l}\text { T1 } \\
\text { hypointense } \\
\text { lesions }(n=21)\end{array}$ & $\begin{array}{l}\text { No } T 1 \\
\text { hypointense } \\
\text { lesions }(n=19)\end{array}$ \\
\hline Baseline ventricular volume $\mathrm{cm}^{3}$ median (range) & $4.3(2.6-23.1)$ & $6.4(1.2-39.2)$ & $7.9(3.1-25.9)$ & $5.9(1.2-39.2)$ & $6(1.2-25.9)$ & $6.9(1.7-39.2)$ \\
\hline One year ventricular volume $\mathrm{cm}^{3}$ median (range) & $4.4(2.4-24.1)$ & $6.8(1.4-40.6)$ & $\begin{array}{l}10.3 \\
(3.2-26.5)\end{array}$ & $6.5(1.4-40.6)$ & $6.7(1.4-26.5)$ & $7(1.7-40.6)$ \\
\hline Ventricular volume change $\mathrm{cm}^{3}$ median (range) & $\begin{array}{l}-0.2 \\
(-0.9-1.0)\end{array}$ & $0.2(-0.7-7.2)$ & $\begin{array}{l}+0.7 \\
(-0.6-7.2)\end{array}$ & $\begin{array}{l}+0.1 \\
(-0.7-1.6)\end{array}$ & $\begin{array}{l}+0.5 \\
(-0.6-7.2)\end{array}$ & $+0.03(-0.7-1.9$ \\
\hline $\begin{array}{l}\text { Comparing baseline and one year ventricular } \\
\text { volumes }\end{array}$ & $p=0.46$ & $P=0.001$ & $p=0.004$ & $p=0.069$ & $p=0.001$ & $p=0.376$ \\
\hline
\end{tabular}


Table 5 Correlation of change in ventricular volume over one year with other MRI lesion measures and with EDSS

\begin{tabular}{lll}
\hline Correlation & r Value & p Value \\
\hline Baseline T2 lesion number & 0.339 & 0.011 \\
Baseline T2 lesion volume & 0.381 & 0.004 \\
Change in T2 lesion volume over one year & 0.202 & 0.138 \\
Sum of baseline and new T2 lesion numbers at one year & 0.386 & 0.006 \\
Number of new T2 lesions at month 12 compared with baseline & 0.254 & 0.061 \\
1 year T2 lesion volume & 0.447 & $0.001^{*}$ \\
Baseline Gd lesion number & 0.354 & 0.008 \\
Month 3 Gd lesion number & 0.367 & 0.007 \\
Baseline and month 3 Gd lesion number & 0.38 & 0.006 \\
Month 12 Gd lesion number & 0.206 & 0.132 \\
Baseline, month 3 and month 12 Gd lesion number & 0.385 & 0.005 \\
Baseline T1 hypointense lesion number & 0.495 & $<0.001^{*}$ \\
Baseline T1 hypointese lesion volume & 0.467 & $<0.001^{*}$ \\
Change in T1 hypointense lesion volume over one year & 0.05 & 0.735 \\
One year T1 hypointense lesion volume & 0.421 & $0.001^{*}$ \\
Baseline EDSS & 0.132 & 0.335 \\
EDSS at month 12 & 0.317 & 0.019 \\
EDSS change over one year & 0.116 & 0.398 \\
\hline *Significant correlations using Bonferroni correction p<0.003. & &
\end{tabular}

Ventricular volumes in the 21 patients with T1 hypointense lesions at baseline showed significant enlargement over the following year $(p=0.001)$, but there was no significant change in the 19 patients who had T2 lesions but no T1 hypointense lesions (table 4).

\section{Correlations (table 5)}

Four correlations were significant using the corrections at $<0.003$ namely the baseline $\mathrm{Tl}$ hypointense lesion number and volume and one year $\mathrm{Tl}$ hypointense and $\mathrm{T} 2$ lesions volumes.

\section{DISCUSSION}

This study has confirmed previous reports in showing that the presence and number of MRI lesions at presentation with a CIS influences the risk of future clinical relapses leading to an early diagnosis of clinically definite or probable MS. Additionally, it revealed ventricular enlargement over one year in the subgroup of patients who developed clinical MS within that period. It also demonstrated ventricular enlargement in the larger cohort of patients with T2 MRI lesions at presentation, the presence of which is associated with a high probability for developing clinically definite MS after prolonged follow up. ${ }^{14-17}$ Finally, the study demonstrated significant, but only modest, correlations between T2 and T1 hypointense lesion load measures and subsequent ventricular enlargement.

A question arising is whether the ventricular enlargement might reflect a reduction in brain water content (pseudo atrophy) rather than true tissue loss. There was no significant difference in the gadolinium enhancing lesion number between the baseline and one year follow up scans (data not shown), so that a spontaneous decrease in the number of inflammatory oedematous lesions did not account for the ventricular enlargement seen. Anti-inflammatory treatments such as corticosteroids or beta interferon can reduce the number of inflammatory oedematous lesions, but in this study only three patients received corticosteroids (one received beta interferon) during the follow up phase.

There have been few studies investigating atrophy in CIS patients. We have previously reported a preliminary study of a small, selected group from within the present larger cohort, consisting of nine patients with T2 lesions at baseline who developed MS during one year of follow up and eight patients with a normal baseline scan who had no further clinical events. In that study we reported significant ventricular enlargement in the subgroup with T2 lesions. ${ }^{18}$ Secondly, we recently have investigated the cervical cord in 43 CIS patients and demonstrated mild but significant atrophy of the upper cervical cord in those patients who had $\mathrm{T} 2$ abnormalities on brain imaging. ${ }^{24}$

This investigation of a large cohort of consecutively recruited CIS cases confirms our preliminary observation in the smaller cohort that early development of ventricular enlargement is associated with further clinical relapses leading to a diagnosis of MS. The development of ventricular atrophy in association with early clinical relapses suggests a potential for this MR measure to provide prognostic data, which needs to be confirmed with long term follow up. There is some evidence from the literature, albeit inconsistent, that relapse rate in the first one to two years after a CIS is related to long term disability. ${ }^{25}$ The relation between early atrophy and long term disability should be investigated by prolonged follow up.

A possible mechanism for the observed ventricular enlargement would be loss of myelin and axons within lesions in itself, and Wallerian degeneration secondary to axonal transection within the lesions. Consistent with this mechanism are the correlations, albeit weak, between the baseline and month 3 number of enhancing lesions and ventricular enlargement. Enhancement is associated with pathological evidence of active inflammation ${ }^{2627}$ and inflammation is associated with axonal damage and transection. ${ }^{28}{ }^{29}$ The small group of patients with enhancing lesions at both baseline and month 3 exhibited more substantial ventricular enlargement. The more aggressive inflammatory disease may have contributed to this.

A modest correlation of ventricular enlargement was also found with baseline T2 and T1 hypointense loads but was somewhat stronger for Tl load. Tl hypointense lesions are associated pathologically with more severe axonal loss,$^{30}$ and thus might be expected to result in a greater degree of secondary Wallerian degeneration and atrophy. It was notable that in the subgroup comparison of those with and without $\mathrm{Tl}$ hypointense lesions at baseline, significant ventricular enlargement was seen only in those with such lesions. Tl hypointense lesions in this study were detected on postcontrast scans - they are thus likely to indicate irreversible changes associated with axonal loss rather than the reversible hypointensity sometimes seen in acute enhancing lesions. The lack of correlation between change in Tl hypointense load over the year and ventricular enlargement may reflect the fact that the magnitude of the former was very small.

As none of the correlations between lesion measures and ventricular enlargement were strong, additional factors may 
contribute to atrophy. One possibility is a more diffuse process involving normal appearing tissues. To date, quantitative MR investigations of normal appearing brain tissues have provided conflicting evidence for abnormality in small CIS cohorts. $^{32-34}$ An MR spectroscopy report demonstrated no significant reduction of NAA in the normal appearing white matter. ${ }^{31}$ Further quantitative MR investigations of the normal appearing brain tissue are needed in larger CIS cohorts.

The technique used in this study does not resolve the site of atrophy. While the MIDAS method used in this study provides a reliable measure of change in whole brain volume on 3D images, we found it less reliable with the present 2D dataset. It is not therefore certain whether atrophy occurs close to lesions, in normal appearing white matter, or in grey matter, although the fact that the ventricles are close to white matter suggests that there may be atrophy in this region. There are alternative strategies for measuring segmented grey and white matter volumes. ${ }^{35}$ Approaches such as voxel based morphometry may depict the regions in which atrophy is occurring. Application of such methods in future studies in CIS patients will be of interest.

The study of atrophy may help to understand the clinical effects of disease modifying treatments for MS. In established disease, beta interferons markedly reduce the rate of new MRI lesions (by 50\%-70\%; IFNB study 1993, ${ }^{36}$ Jacobs 1996, ${ }^{37}$ PRISMS $1998^{38}$ ), but they have a smaller effect in preventing relapses, disability and atrophy. ${ }^{39}{ }^{40}$ Future reports of the effect of treatment on atrophy in CIS patients are awaited, but this work highlights the potential for a mechanism of clinical deterioration that is independent of lesions.

While these results suggest that atrophy is occurring at the earliest clinical stage of MS, a direct comparison with other studies at a later stage is not possible, because the methodology involved has differed. There are a number of sensitive and reproducible methods for detecting brain atrophy but they may produce quite a different absolute measure of change. ${ }^{7}$ Further study of cohorts with later disease using the same MR acquisition and analysis method for measuring ventricular enlargement is now being undertaken.

Further follow up of the CIS cohort is now needed to determine the longer term evolution of atrophy, and its relation to lesion evolution, quantitative MR changes in the normal appearing tissues, and clinical outcome.

In conclusion, this study reveals two MR features in patients with CIS who go onto develop early clinical MS-lesions and atrophy. While lesions contribute to atrophy, the correlation is modest, suggesting that the latter also develops by other mechanisms. Both lesions and atrophy are therefore complementary methods for monitoring the course of MS, even from its earliest stages.

\section{ACKNOWLEDGEMENTS}

We thank Dr Martin King for his help with the statistical analysis.

\section{Authors' affiliations \\ C M Dalton, P A Brex, J I O'Riordan, A J Thompson, D H Miller NMR Research Unit, Institute of Neurology, London, UK \\ R Jenkins, N C Fox, W R Crum, Dementia Research Group, Institute of Neurology, London, UK \\ K A Miszkiel, Lysholm Department of Neuroradiology, National Hospital for Neurology and Neurosurgery, London, UK \\ G T Plant, Moorfields Eye Hospital, London, UK}

Funding: The NMR Research Unit receives a programme grant from the MS Society of Great Britain and Northern Ireland. Dr Dalton is supported by Elan Pharma. Drs Brex and O'Riordan were supported by Schering AG. Dr Fox holds an MRC Clinical Scientist Fellowship and Dr Crum is supported as part of an MRC programme grant.

Competing interests: none declared

\section{REFERENCES}

1 Gross KR, Tomberg TA, Kokk AA, et al. The prognosis of multiple sclerosis: computed tomographic comparisons. Zh Nevropatol Psikhiatr Im S S Korsakova 1993:93:32-5.

2 Davie CA, Barker GJ, Webb S, et al. Persistent functional deficit in multiple sclerosis and autosomal dominant cerebellar ataxia is associated with axon loss. Brain 1995;118:1583-92.

3 Liu C, Edwards S, Gong Q, et al. Three-dimensional MRI estimates of brain and spinal cord atrophy in multiple sclerosis. J Neurol Neurosurg Psychiatry 1999;66:323-30

4 Filippi $M$, Colombo B, Rovaris $M$, et al. A longitudinal magnetic resonance imaging study of the cervical cord in multiple sclerosis. J Neuroimaging 1997; 7:78-80

5 Losseff NA, Webb SL, O'Riordan Jl, et al. Spinal cord atrophy and disability in multiple sclerosis. A new reproducible and sensitive MRI method with potential to monitor disease progression. Brain 1996; 119:701-8.

6 Fox NC, Jenkins R, Leary SM, et al. Progressive cerebral atrophy in MS: a serial study using registered, volumetric MRI. Neurology 2000:54:807-12.

7 Miller DH, Barkhof F, Frank JA, et al. Measurement of atrophy in multiple sclerosis: pathological basis, methodological aspects and clinical relevance. Brain (in press).

8 Coles AJ, Wing MG, Molyneux P, et al. Monoclonal antibody treatment exposes three mechanisms underlying the clinical course of multiple sclerosis. Ann Neurol 1999:46:296-304.

9 Collins DL, Narayanan S, Caramanos Z, et al. Relation of cerebral atrophy in multiple sclerosis to severity of disease and axonal injury. Neurology 2000;54 (suppl 3):A17

10 Kalkers NF, Bergers L, de Groot V, et al. Concurrent validity of the MS functional composite using MRI as a biological disease marker. Neurology 2001:56:215-19.

11 Losseff NA, Kingsley DP, McDonald WI, et al. Clinical and magnetic resonance imaging predictors of disability in primary and secondary progressive multiple sclerosis. Mult Scler 1996;1:218-22.

12 Losseff NA, Wang L, Lai HM, et al. Progressive cerebral atrophy in multiple sclerosis. A serial MRI study. Brain 1996:119:2009-19.

13 Paolillo A, Pozzilli C, Gasperini C, et al. Brain atrophy in relapsing-remitting multiple sclerosis: relationship with 'black holes', disease duration and clinical disability. J Neurol Sci 2000;174:85-91.

14 O'Riordan JI, Thompson AJ, Kingsley DP, et al. The prognostic value of brain MRI in clinically isolated syndromes of the CNS. A 10-year follow-up. Brain 1998;121:495-503.

15 Brex PA, Ciccarelli O, O'Riordan Jl, et al. A longitudinal study of abnormalities on MRI and disability from multiple sclerosis. N Engl J Med 2002;346: 158-64.

16 Ghezzi A, Martinelli V, Torri V, et al. Long-term follow-up of isolated optic neuritis: the risk of developing multiple sclerosis, its outcome, and the prognostic role of paraclinical tests. J Neurol 1999;246:770-5.

17 Optic Neuritis Study Group. The 5-year risk of MS after optic neuritis. Experience of the optic neuritis treatment trial. Optic Neuritis Study Group. Neurology 1997;49:1404-13.

18 Brex PA, Jenkins R, Fox NC, et al. Detection of ventricular enlargement in patients at the earliest clinical stage of MS. Neurology 2000:54:1689-91.

19 Kurtzke JF. Rating neurologic impairment in multiple sclerosis: an expanded disability status scale (EDSS). Neurology1983;33:1444-52.

20 Poser CM, Paty DW, Scheinberg L, et al. New diagnostic criteria for multiple sclerosis: guidelines for research protocols. Ann Neurol 1983:13:227-31.

21 McDonald WI, Compston DAS, Edan G, et al. Recommended diagnostic criteria for multiple sclerosis: guidelines from the International Panel on the diagnosis of multiple sclerosis. Ann Neurol 2001;50:121-7.

22 Freeborough PA, Fox NC, Kitney RI. Interactive algorithms for the segmentation and quantitation of 3-D MRI brain scans. Comput Methods Programs Biomed 1997;53:15-25.

23 Plummer DL. Dispimage: a display and analysis tool for medical images. Riv Neuroradiol 1992;5:489-95.

24 Brex PA, Leary SM, O'Riordan JI, et al. Measurement of spinal cord area in clinically isolated syndromes suggestive of MS. J Neurol Neurosurg Psychiatry 2001;70:544-7.

25 Weinshenker BG, Bass B, Rice GP, et al. The natural history of multiple sclerosis: a geographically based study. 2 . Predictive value of the early clinical course. Brain 1989;112:1419-28.

26 Katz D, Taubenberger JK, Cannella B, et al. Correlation between magnetic resonance imaging findings and lesion development in chronic, active multiple sclerosis. Ann Neurol 1993;34:661-9.

27 Bruck W, Bitsch A, Kolenda $\mathrm{H}$, et al. Inflammatory central nervous system demyelination: correlation of magnetic resonance imaging findings with lesion pathology. Ann Neurol 1997;42:783-93.

28 Ferguson B, Matyszak MK, Esiri MM, et al. Axonal damage in acute multiple sclerosis lesions. Brain 1997; 120:393-9.

29 Trapp BD, Peterson J, Ransohoff RM, et al. Axonal transection in the lesions of multiple sclerosis. N Engl J Med 1998;338:278-85.

30 Van Waesberghe JH, Kamphorst W, De Groot CJ, et al. Axonal loss in multiple sclerosis lesions: magnetic resonance imaging insights into substrates of disability. Ann Neurol 1999:46:747-54.

31 Brex PA, Gomez-Anson B, Parker GJ, et al. Proton MR spectroscopy in clinically isolated syndromes suggestive of multiple sclerosis. J Neurol Sci 1999; 166:16-22.

32 Brex PA, Leary SM, Plant GT, et al. Magnetization transfer imaging in patients with clinically isolated syndromes suggestive of multiple sclerosis. Am J Neuroradiol 2001;22:947-51. 
33 Kaiser JS, Grossman RI, Polansky M, et al. Magnetization transfer histogram analysis of monosymptomatic episodes of neurologic dysfunction: preliminary findings. Am J Neuroradiol 2000;21:1043-7.

34 Iannucci G, Tortorella $C$, Rovaris $M$, et al. Prognostic value of MR and magnetization transfer imaging findings in patients with clinically isolated syndromes suggestive of multiple sclerosis at presentation. $\mathrm{Am} J$ Neuroradiol 2000;21:1034-8.

35 Chard DT, Parker GJ, Griffin CM, et al.The reproducibility and sensitivity of brain tissue volume measurements derived from an SPM-based segmentation methodology. J Magn Reson Imaging 2002;15:259-67.

36 Paty DW, Li DK. Interferon beta-1b is effective in relapsing-remitting multiple sclerosis. II. MRI analysis results of a multicenter, randomized, double-blind, placebo-controlled trial. UBC MS/MRI Study Group and the IFNB Multiple Sclerosis Study Group. Neurology 1993;43:662-7.

37 Jacobs LD, Cookfair DL, Rudick RA, et al. Intramuscular interferon beta-la for disease progression in relapsing multiple sclerosis. The
Multiple Sclerosis Collaborative Research Group (MSCRG). Ann Neurol 1996;39:285-94

38 PRISMS. (Prevention of Relapses and Disability by Interferon beta-la Subcutaneously in Multiple Sclerosis) Study Group. Randomised double-blind placebo-controlled study of interferon beta- $1 \mathrm{a}$ in relapsing/remitting multiple sclerosis. Lancet 1998;352:1498-504.

39 Rudick RA, Fisher $\mathrm{E}$, Lee JC, et al. Use of the brain parenchymal fraction to measure whole brain atrophy in relapsing -remitting MS. Multiple Sclerosis Collaborative Research Group. Neurology 1999;53:1698704.

40 Molyneux PD, Kappos L, Polman C, et al. The effect of interferon beta- $1 \mathrm{~b}$ treatment on MRI measures of cerebral atrophy in secondary progressive multiple sclerosis. European Study Group on Interferon beta- $1 \mathrm{~b}$ in secondary progressive multiple sclerosis. Brain 2000; 123:2256-63.

\title{
NEUROLOGICAL STAMP
}

\author{
Hideyo Noguchi (1876-1928)
}

T

he Japanese born microbiologist Hideyo Noguchi's brilliant career had humble origins. He was born in the village of Sanjogata. His

father, the village postman, and his mother toiling in the rice fields barely made a living. A childhood accident with a pot of simmering rice burnt his left arm and hand and caused deformity and scarring. When a school inspector named Kobayashi visited the village school, he noticed Noguchi was gifted and arranged for him to attend his high school in a neighbouring town. He also sent him to a Doctor Watanabe in a nearby town, who divided the scars of his mutilated left hand. This gave Noguchi's stiff fingers some limited movement. Watanabe took on the boy as an assistant and dispenser of medicines and gave him the chance to learn medicine through apprenticeship, as was customary at the time. In Watanabe's house he learnt English and German and, using Watanabe's microscope, Noguchi observed a new organism from a patient with relapsing fever that looked like a corkscrew. That corkscrew germ haunted him for years.

Eventually, Noguchi entered medical school in Tokyo and obtained his diploma 1897. Later he entered the Institute for Infectious Diseases in Tokyo, whose director Kitasato had studied under Robert Koch in Berlin, and had discovered the organisms of tetanus and plague. At the institute, Noguchi met Professor Simon Flexner visiting from Philadelphia and on the strength of the little English he knew, Noguchi's had the responsibility of showing him round.

In 1899 Noguchi came to Philadelphia, and started work at the University of Pennsylvania, studying venoms. Noguchi was awarded a Carnegie Fellowship and in 1904 studied in Copenhagen under a leading European authority, Thorwold Madsen. It was in Denmark that Noguchi produced an anti-toxin to snakebite. When Flexner was appointed director of the newly formed Rockefeller Institute for Medical Research in New York, he asked Noguchi to join his staff. Here he successfully cultured the spirochete Treponema Pallidum, the cause of syphilis and also proposed a modification of the Wassermann reaction. Noguchi found the spirochete in parts of the human nervous system and the human brain, in diseases previously not thought to be connected with syphilis. He was able to show that T Pallidum invaded the nervous system as the disease progresses.

Noguchi later investigated other diseases. He was interested in poliomyelitis, rabies, and trachoma and invented the term leptospira, or delicate spiral organism. This spirochete had been identified by two Japanese bacteriologists and had been shown to cause of infective jaundice in the rice fields of Japan. He studied Oroya fever in South and Central America and showed it was caused by a bacterium, Baron-

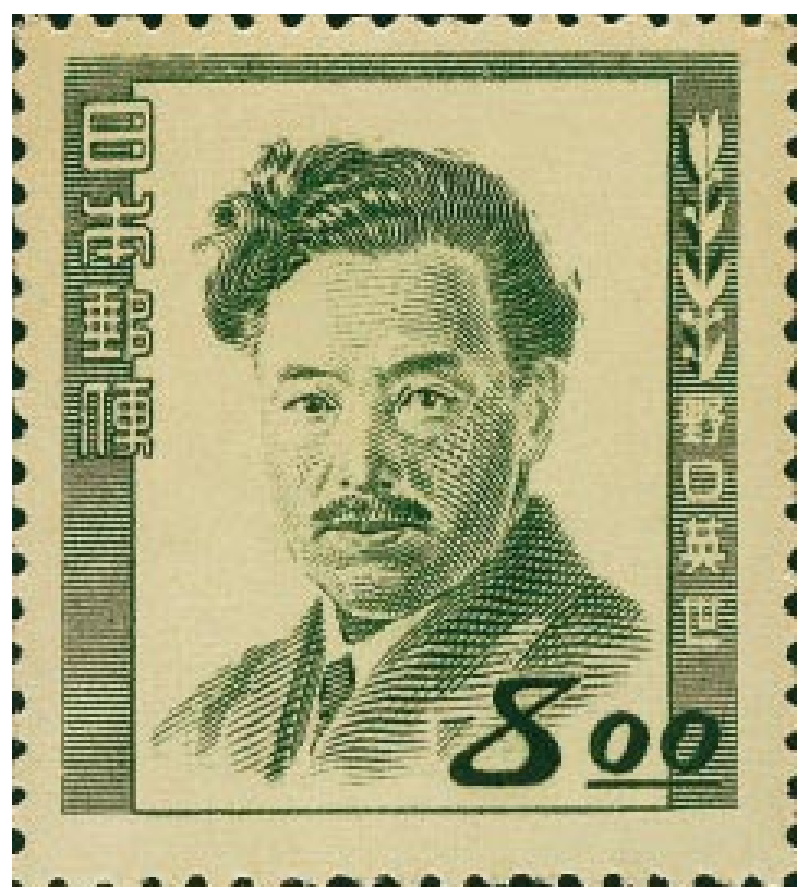

ella bacilliformis. Between 1919 and 1922, Noguchi became certain that yellow fever was caused by a bacterium, but by 1927 this had been disproved. Noguchi went to West Africa to prove to himself that yellow fever was a viral disease. Within six months he had confirmed this, but just before his departure for New York he contracted yellow fever and died shortly afterwards in what is now Ghana. He was philatelically honoured by Ghana in 1997 on the 120th anniversary of his birth and earlier by Japan in 1949 (Stanley Gibbons no. 557, Scott no. 480).

LF Haas 